\title{
Comparison of postoperative ciliary body changes associated with the use of 23- gauge and 20-gauge system for pars plana vitrectomy
}

\author{
Meng-su Tang ${ }^{1}$, Shu-qi Zhang ${ }^{2}$ and Li-wei Ma ${ }^{1 *}$ (1)
}

\begin{abstract}
Background: To compare the ciliary body changes associated with the use of 23-gauge (23G) and 20-gauge (20G) systems for pars plana vitrectomy.

Methods: A total of 60 patients (60 eyes) with idiopathic epiretinal membrane who were scheduled for surgical treatment were selected and randomly assigned to $20 \mathrm{G}$ group or 23G group. Time required for incision making, vitrectomy, and incision closure was compared between the two groups. Changes in ciliary body were evaluated by ultrasound microscopy (UBM). Anterior chamber inflammation was assessed with laser flare meter instrument.

Results: Incision-making time ( $4.5 \pm 0.9 \mathrm{~min})$ and incision-closure time $(2.8 \pm 0.7 \mathrm{~min})$ in the $23 \mathrm{G}$ group were significantly shorter than those in the $20 \mathrm{G}$ group (10.1 $\pm 1.5 \mathrm{~min}$ and $11.3 \pm 2.2 \mathrm{~min}$, respectively). No significant intergroup difference was observed with respect to time required for vitrectomy (21.6 $\pm 3.3 \mathrm{~min}$ and $20.7 \pm 3.2 \mathrm{~min}$, respectively). Ciliary body thickness in the $23 \mathrm{G}$ group recovered back to preoperative levels after 4 weeks, as against 8 weeks in the $20 \mathrm{G}$ group. Postoperative ciliary body thickness in the 20G group was significantly higher than that in the 23G group $(p<0.05)$. The aqueous protein concentration in $23 \mathrm{G}$ group recovered back to preoperative levels after 2 weeks, as against 4 weeks in the $20 \mathrm{G}$ group. Postoperative aqueous protein concentration in the $20 \mathrm{G}$ group was significantly higher than that in the 23G group $(p<0.05)$.

Conclusions: The use of $23 \mathrm{G}$ system was associated with significantly milder injury to the ciliary body as compared to that associated with the use of $20 \mathrm{G}$ system.

Trial registration: The study was retrospectively registered on Chinese Clinical Trial Registry. The clinical study registration number was ChiCTR-INR-17011082. Date of registration: 2017-04-07.
\end{abstract}

Keywords: Pars plana vitrectomy, Ciliary body, Idiopathic epiretinal membrane, 23-gauge system

\section{Background}

Technological advancements in vitreoretinal surgery have made it possible to treat certain diseases which were hitherto considered untreatable. Pioneered by Machemer in the early 1970s, the pars plana vitrectomy technique has evolved into an increasingly advanced minimally-invasive treatment modality. Introduced for the first time by Claus

\footnotetext{
* Correspondence: Iwma@cmu.edu.cn

${ }^{1}$ Department of Ophthalmology, the Fourth Affiliated Hospital of China Medical University, No. 11 Xinhua Road, Heping District, Shenyang 110004, Liaoning Province, China

Full list of author information is available at the end of the article
}

Eckardt in 2005, the 23-gauge (23G) transconjunctival vitrectomy technique is commonly used by vitreoretinal surgeons in daily practice. The advantages of use of $23 \mathrm{G}$ system include a smaller incision, milder inflammatory response, and more rapid recovery [1-5]. However, use of 23G system may lead to low intraocular pressure, choroidal detachment, and incisional vitreous incarceration in the short term after the procedure [6-8].

Pars plana vitrectomy is a safe procedure used to manage vitreoretinal disease. However, it could also alter the anterior segment morphology and increase the risk of early postoperative complications such as transient

(C) The Author(s). 2018 Open Access This article is distributed under the terms of the Creative Commons Attribution 4.0 International License (http://creativecommons.org/licenses/by/4.0/), which permits unrestricted use, distribution, and 
decrease in depth of anterior chamber, angle narrowing, persistent hypotony, and supraciliary effusion [9-11]. The underlying retinal microangiopathy increases the risk of postoperative inflammation, uveal congestion, and changes of the ciliary body in patients with vitreoretinal disease; these changes may be severe in some cases. However, clinical evidence pertaining to post-vitrectomy changes of the ciliary body in such patients is not well documented.

Ultrasound biomicroscopy has been used to monitor postoperative incision healing after use of $20 \mathrm{G}$ and $25 \mathrm{G}$ vitrectomy systems, [12-15] by serial measurements of the thickness of the ciliary body. In addition, laser flare meter provides a non-invasive means for quantitative monitoring of blood-aqueous barrier function, through laser reflection of the anterior pupil area to indicate the aqueous protein concentration; the technique allows for evaluation of ciliary body wound healing from another aspect [16-18]. In this study, changes of ciliary body thickness and aqueous protein concentration before and after operation were studied to explore the impact on 23G and 20G vitrectomy.

\section{Methods}

\section{Objects}

A total of 60 patients (60 eyes) with idiopathic epiretinal membrane, who underwent surgical treatment at our hospital during January 2016 and February 2017 were selected. The patients included 22 men and 38 women (age range, 39 to 60 years). The subjects were randomly assigned to 23G group or 20G group using a random number table. No statistical difference was observed on age and gender distribution between two groups. Patients in the $23 \mathrm{G}$ group received $23 \mathrm{G}$ minimally invasive vitrectomy and those in the 20G group received 20G traditional standard three-channel vitrectomy. Written informed consent was obtained from all patients prior to their enrolment. The study was approved by the institutional ethics committee. The clinical study registration number was ChiCTR-INR-17011082.

Inclusion criteria: (1) idiopathic epiretinal membrane diagnosed based on optical coherence tomography and fundus fluorescein angiography; (2) best corrected visual acuity $\leq 0.3$; (3) diopter between $\pm 3.0 \mathrm{D}$.

Exclusion criteria: (1) history of eye surgery; (2) glaucoma, familial glaucoma history, or intraocular hypertension; (3) uveitis; (4) severe lenticular opacity requiring cataract extraction; (5) need for intraocular tamponade, such as silicone oil or gas; (6) patients with diabetes, hypertension, and autoimmune conditions, such as rheumatoid arthritis, systemic lupus erythematosus, and multiple sclerosis.

\section{Operation method}

All patients were operated under general or local anesthesia by the same surgeon (L.M.). Vitrectomy machine system
(ACCURUS, ALCON) was used for 23-gauge vitrectomy and 20-gauge vitrectomy. In the 23G group, the conjunctiva was pushed laterally using a pressure plate. Subsequently, two-step tunnel-like transconjuctival incisions were made using a sharp $23 \mathrm{G}$ blade at a $20-30^{\circ}$ angle parallel to the limbus facilitating insertion of the trocars. After vitrectomy, the trocars were removed and the sclerotomies were covered by the conjunctiva.

In the $20 \mathrm{G}$ group, the conjunctiva was opened in a nasal triangle and a temporal quadrangle $1 \mathrm{~mm}$ from the limbus followed by scleral incisions $3.5-4 \mathrm{~mm}$ behind the limbus without electrocoagulation. After vitrectomy, the sclerotomies and conjunctiva were closed with vicryl 8.0 sutures. In both groups, a thorough vitrectomy was performed with the goal of removing vitreous. Time required for incision-making, vitrectomy, and - incisionclosure was recorded for all patients.

All patients were administered topical levofloxacin 6 times per day and atropine ophthalmic gel 2 times per day from 3 days before the operation. After the operation, the subjects received topical tobramycin dexamethasone 4 times per day and atropine ophthalmic gel 2 times per day. The tobramycin dexamethasone was tapered off over 4 weeks and changed to pranoprofen 4 times per day for another 4 weeks. Atropine ophthalmic gel was stopped after 2 weeks.

\section{Postoperative observation}

The evaluation of ciliary body by ultrasound microscopy (UBM) (ODM-3000, Tianjin Meda Medical Technology Co., Ltd.) was performed by the same technician. The ciliary body thickness at three incisions was measured to obtain the mean value. Each measurement was repeated three times to calculate the mean value. Ethylene oxide was used to sterilize the eye cup and absolute alcohol was adopted to wipe the UBM probe. Anterior chamber inflammation was detected by laser flare meter(FM600, Kowa) to measure the aqueous protein concentration. Each measurement was repeated three times to calculate the mean value. All subjects were assessed with UBM and laser flare meter preoperatively, on postoperative day 1, week 1 , week 2 , and week 4. UBM examination was performed again at the postoperative week 8 .

\section{Statistical analysis}

All data analyses were performed with SPSS 19.0 software(IBM Corporation, NY). The ciliary body thickness and aqueous protein concentration before and after the operation were compared by two-way ANOVA. Ciliary body thickness, aqueous protein concentration, and operation time of the two groups were compared by $t$ test. $p<0.05$ was considered statistically significant. 


\section{Results}

\section{General information}

The baseline demographic data of the two groups were listed in Table 1. The lens was not exceed C1N1P0 according to LOCSII classification.

\section{Complications}

Eight patients in the $23 \mathrm{G}$ group and six patients in the $20 \mathrm{G}$ group developed punctate hemorrhage in the macular area. The bleeding was self-absorbed without laser or electrocoagulation intervention. The lens was retained in all patients, and no intraocular tamponade was used at the end of surgery. Six patients in the 23G group experienced mild choroidal detachment on the first day after operation, which recovered in one week. However, none of the patients in the 20G group experienced choroidal detachment. Fifteen patients in the 23G group and two patients in the 20G group had low intraocular pressure on the first postoperative day and recovered in one week. Vitreous incarceration was observed in $3(10 \%, 23 G)$ and $0(0 \%, 20 G)$ eyes on the first postoperative day. None of the patients developed postoperative endophthalmitis.

\section{Time for surgery}

The 23G group exhibited significantly shorter time for incision-making $(4.5 \pm 0.9 \mathrm{~min})$ and incision-closure $(2.8$ $\pm 0.7 \mathrm{~min})$ as compared to that in the 20G group (10.1 \pm $1.5 \mathrm{~min}$ and $11.3 \pm 2.2 \mathrm{~min})$, respectively $(t=17.771, p<$ $0.05 ; t=19.868, p<0.05)$. No statistically significant intergroup difference was observed with respect to time for vitrectomy $(21.6 \pm 3.3 \mathrm{~min}$ vs. $20.7 \pm 3.2 \mathrm{~min}, t=$ 1.038, $p>0.05)$.

\section{Measurement of ciliary body thickness}

As shown in Fig. 1a, no significant intergroup difference was observed with respect to preoperative ciliary body thickness $(t=0.064, p>0.05)$. A significant increase in ciliary body thickness was observed postoperatively in both groups $(F=263.83, p<0.05)$. Ciliary body thickness in the $23 \mathrm{G}$ group recovered to preoperative levels after 4 weeks as against 8 weeks in the $20 \mathrm{G}$ group.

Table 1 Patient demographic data

\begin{tabular}{lll}
\hline & $23 G$ & $20 G$ \\
\hline Cases(eye) & 30 & 30 \\
Mean age & 52 & 51 \\
Age range & $39-60$ & $41-60$ \\
Male & 10 & 12 \\
Female & 20 & 18 \\
$\begin{array}{l}\text { preoperative ciliary body } \\
\text { thickness (mm) } \\
\text { preoperative aqueous } \\
\text { protein concentration (pc/ms) }\end{array}$ & $0.25 \pm 0.02$ & $0.25 \pm 0.02$ \\
\hline
\end{tabular}

Postoperative ciliary body thickness in the 20G group was significantly higher than that in the $23 \mathrm{G}$ group $(\mathrm{F}=$ $18.913, p<0.05)$. The measurement method of ciliary body thickness was exhibited in Fig. 2.

\section{Measurement of aqueous protein concentration}

As shown in Fig. 1b, no significant intergroup difference was observed with respect to preoperative aqueous protein concentration $(t=0.592, p>0.05)$. A significant increase in aqueous protein concentration was observed postoperatively in both groups $(\mathrm{F}=117.246, p<0.05)$. Aqueous protein concentration in the $23 \mathrm{G}$ group recovered to preoperative levels in 2 weeks as against 4 weeks in the 20G group. Aqueous protein concentration in the $20 \mathrm{G}$ group was significantly higher than that in the $23 \mathrm{G}$ group $(\mathrm{F}=7.775, p<0.05)$.

\section{Discussion}

Minimal-invasive procedures are the tendency of modern ocular surgery. According to many previous studies, sutureless vitrectomy has its benefits and risks. The sutureless vitrectomy system shortens the operation time to some extent, thus providing quicker recovery time. However, low intraocular pressure and ciliary body detachment may appear in the early stage of postoperative period [19-21].

In our study, small-incision vitrectomy(23G) was associated with shorter operation time and faster postoperative recovery. This mirrors the results of previous studies [19-21]. 23G system with the wider cutter opening and much closer to the cutter head can not only increase the cutting rate, but also reduce the unnecessary disturbances to the retina which makes up its lower efficiency due to the thinner pipe. This is proven by the result of our study that the vitrectomy time was no significant difference in $20 \mathrm{G}$ and $23 \mathrm{G}$ groups. Due to the shorter incision-making and incision-closure time, the total operation time was much shorter in 23G group..

Previous studies mainly focused on ciliary body detachment and vitreous incarceration. However, it is less investigated about the impact of the two systems on the thickness of ciliary body. In this study, we focused on the quantative change of ciliary body at the incision site. In addition, all the patients retained the lens, which helped avoid thermal damage caused by phacoemulsification. Furthermore, no silicone oil or gas tamponade were used in these cases, which avoids the impact of intraocular tamponade on the ciliary body. The ciliary body changes were mainly caused by the two different vitrectomy systems. The results of this study indicated postoperative increase in thickness of the ciliary body in both the groups; however, the amplitude of increase in the $23 \mathrm{G}$ group was significantly lower than that in the 20G group. Additionally, the ciliary body thickness 

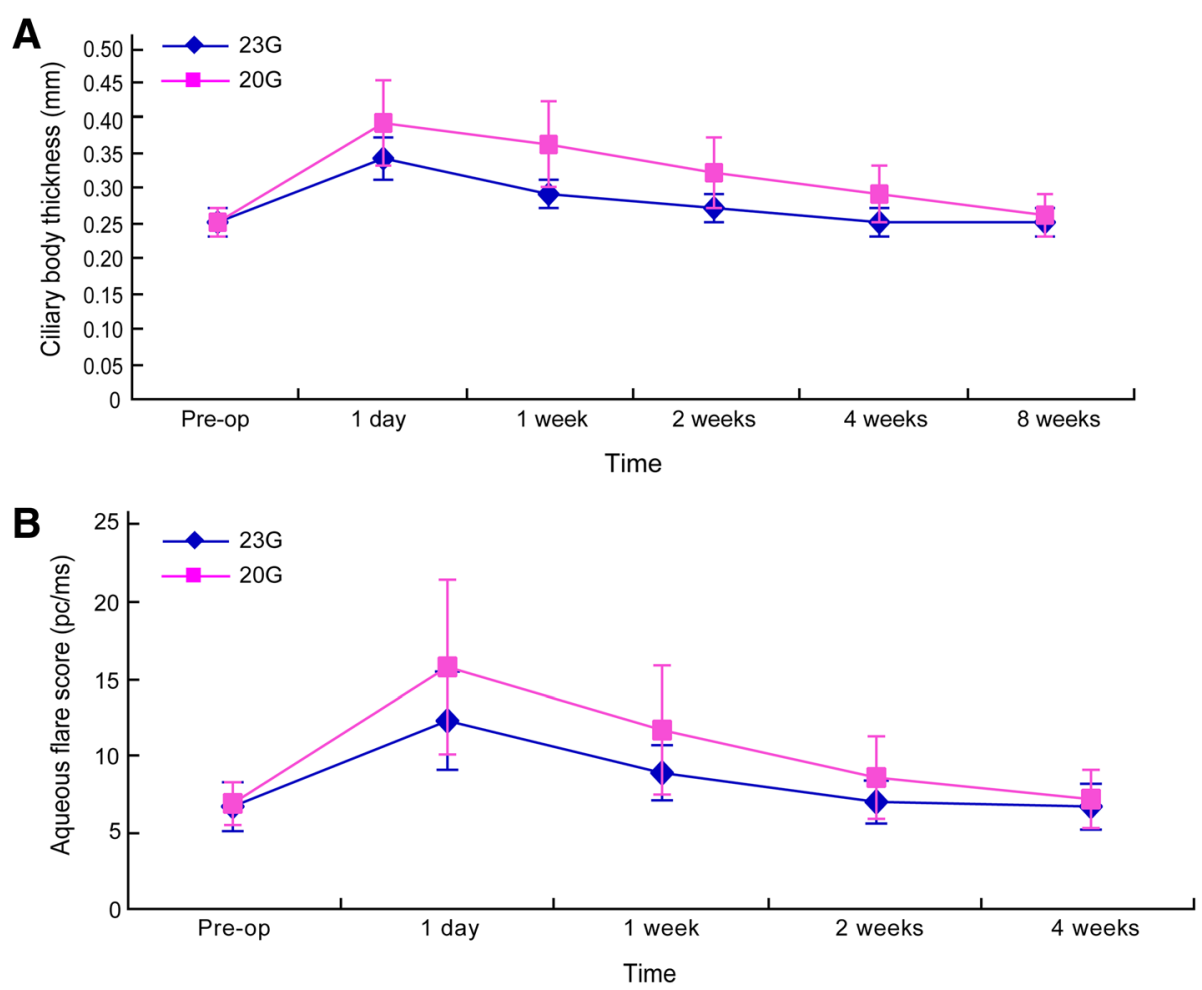

Fig. 1 Postoperative changes of ciliary body thickness and aqueous flare score. a, ciliary body thickness. b, aqueous flare score

recovered to the preoperative level after two weeks in 23G group, as compared to 4 weeks in the 20G group, which suggests that $23 \mathrm{G}$ vitrectomy system caused lesser damage to the ciliary body. This is attributable to several factors. Firstly, compared with the traditional 20G system, 23G vitrectomy system enters the eye through the trocar fixed on pars plana of the ciliary body, without direct contact with the sclera and the ciliary body. The trocar helped avoid the direct contact of surgical instruments with the ciliary body. The lesser friction of the surgical instruments minimized the mechanical damage to the ciliary body. Secondly, the presence of a part of the trocar in the eye effectively reduces intraoperative vitreous spillover and the

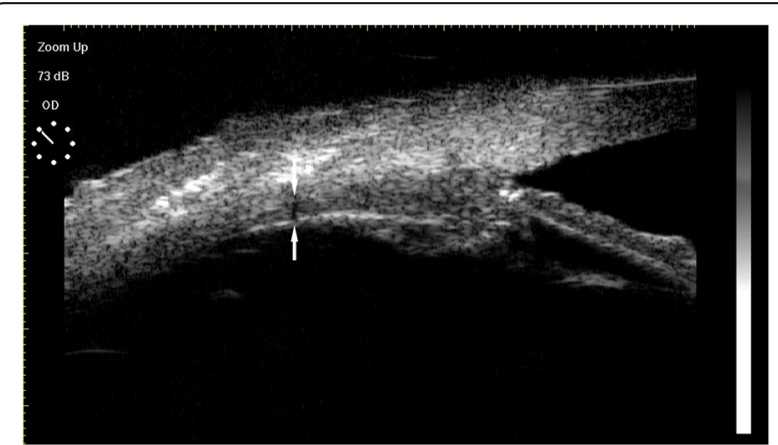

Fig. 2 Ciliary body thickness in $20 \mathrm{G}$ group at 4 weeks after surgery detected by UBM (arrow) traction effect of the ciliary body in the vicinity of the incision site. In the 20G group, 4 patients, who were found that part of the pigment epithelium of ciliary body was brought out together with the spilled vitreous, experienced a particularly high degree of postoperative increase in ciliary body thickness. Thirdly, a conjunctival oblique incision (two-step method) was applied in 23G group, which was subject to automatic closure and required no suture. On the contrary, incisions in the 20G group were closed by absorbent suture. Granulomatous inflammation during degradation of the suture may affect the repair of the ciliary body, and prolong the time required for recovery of ciliary body. Though previous studies did not involve direct observation of ciliary body damage after pars plana vitrectomy, several studies indicate that unsutured vitrectomy is associated with lesser postoperative inflammation and shorter recovery time, which is consistent with our results $[22,23]$.

The blood-aquoeus barrier function is disturbed after trauma or surgery. The operation-induced blood-aquoeus barrier dysfunction may be related to mechanical damage and thermal injury.. None of the patients in this study received retinal photocoagulation treatment or cataract phacoemulsification, which helped exclude the impact of thermal injury. Blood-aquoeus barrier dysfunction may be mainly caused by mechanical damage in the anterior uvea. We employed laser flare meter to measure aqueous 
protein concentration in order to assess the degree of damage to the blood-aquoeus barrier function. Smaller incisions for cataract surgery have been shown to attenuate damage to the blood-aquoeus barrier function as compared to larger incisions [24, 25]. In this study, postoperative aqueous protein concentrations were increased to varying degrees in both the groups, which indicates that all patients suffered from blood-aquoeus barrier function damage because of mechanical injury. However, the increasement of aqueous protein concentration in the 23G group was significantly smaller than that in the $20 \mathrm{G}$ group, which suggests that mechanical injury to the ciliary body in the $23 \mathrm{G}$ group was lesser than that in the $20 \mathrm{G}$ group. In addition, the time required for aqueous protein concentration recovery was 2 weeks in the 23G group and 4 weeks in the $20 \mathrm{G}$ group, which further demonstrates that $23 \mathrm{G}$ vitrectomy system was relatively less invasive.

Besides the benefits of sutureless vitrectomy discussed above, there still some risks of it are worth of attention. The incidence of hypotony and choroidal detachment in the 23G group was significantly higher than that in the 20G group, which was associated with intraoperative fluid filler and postoperative incision leakage [26, 27]. According to our results, the higher incidence of hypotony and choroidal detachment in $23 \mathrm{G}$ group mostly happened in the early postoperative stage, and this transient phenomenon can be restored in about 1 week. While the thickness of ciliary body recovered in 4 weeks in $23 \mathrm{G}$ group compared with 8 weeks in $20 \mathrm{G}$ group, the transient postoperative hypotony and choroidal detachment did not affect the recovery of ciliary body's morphology and function. Theoretically, sutureless surgical procedures are associated with a higher risk of endophthalmitis. However, no case of endophthalmitis occurred in our study, although the number of patients is too small to draw any definitive conclusions in this respect.

\section{Conclusions}

In summary, compared with the $20 \mathrm{G}$ vitrectomy system, the $23 \mathrm{G}$ vitrectomy system apparently reduced the total operation time owing to faster incision-making and closure. The use of the 23G system was associated with significantly less damage to the ciliary body as compared to the use of $20 \mathrm{G}$ system.

\section{Abbreviation}

UBM: Ultrasound microscopy

\section{Acknowledgements}

Ming-yu Shi and Fan Zhang contributed equally to this work.

Funding

This study was not supported by any research grants.

\section{Availability of data and materials}

The datasets used and/or analyzed during the current study are available from the corresponding author on reasonable request (Iwma@cmu.edu.cn).

\section{Authors' contributions}

Meng-su Tang analyzed the data and wrote the manuscript. Shu-qi Zhang analyzed the data and wrote the manuscript. Li-wei Ma designed the study, analyzed and interpreted the patient data, and was a major contributor in

writing the manuscript. All authors read and approved the final manuscript.

\section{Ethics approval and consent to participate}

This study followed the tenets of the Declaration of Helsinki and approved by the institutional ethics committee of the Fourth Affiliated Hospital of China Medical University. Informed written consent was obtained from all participants.

Consent for publication

Not applicable.

\section{Competing interests}

The authors declare that they have no competing interests.

\section{Publisher's Note}

Springer Nature remains neutral with regard to jurisdictional claims in published maps and institutional affiliations.

\section{Author details}

${ }^{1}$ Department of Ophthalmology, the Fourth Affiliated Hospital of China Medical University, No. 11 Xinhua Road, Heping District, Shenyang 110004, Liaoning Province, China. ${ }^{2}$ Department of Ophthalmology, the 463 Hospital of the Chinese People's Liberation Army, Shenyang 110021, Liaoning Province, China.

Received: 8 June 2018 Accepted: 19 September 2018

Published online: 11 October 2018

\section{References}

1. Karadag R, Gunes B, Demiorok A. Trocar-assisted intrascleral sutureless fixation of a dislocated three-piece sulcus intraocular lens. Arq Bras Oftalmol. 2017;80(6):393-5.

2. Gurelik G, Sul S, Kilic G, Ozsaygili C. A modified foveal advancement technique in the treatment of persistent large macular holes. Ophthalmic Surg Lasers Imaging Retina. 2017:48(10):793-8.

3. Bajgai $P$, Tigari $B$, Singh R. Outcomes of 23- and 25-gauge transconjunctival sutureless vitrectomies for dislocated intraocular lenses. Int Ophthalmol. 2017.

4. Hsu CM, Chen SC, Wu TT, Sheu SJ. Outcomes of 23-gauge transconjunctival sutureless vitrectomy for acute postoperative endophthalmitis. J Chin Med Assoc. 2017;80(8):503-7.

5. Dehghani A, Rezaei L, Tavallali A, Dastborhan Z. Upper eyelid silicone oi migration after Sutureless 23-gauge vitrectomy. Advanced biomedical research. 2017:26:58.

6. Kucuk E, Yilmaz U, Zor KR, Kalayci D, Sarikatipoglu H. Risk factors for suture requirement and early hypotony in 23-gauge vitrectomy for complex vitreoretinal diseases. Int Ophthalmol. 2017;37(4):989-94.

7. $\mathrm{Xu} \mathrm{H}$, Lutrin D, Wu Z. Outcomes of 23-gauge pars plana vitrectomy combined with phacoemulsification and capsulotomy without intraocular lens implantation in rhegmatogenous retinal detachment associated with choroidal detachment. Medicine. 2017:96(34):e7869.

8. Takashina H, Watanabe A, Mitooka K, Tsuneoka H. Examination of selfsealing Sclerotomy for Vitrectomized eye under gas tamponade in 23 gauge Transconjunctival Sutureless vitrectomy. Semin Ophthalmol. 2016; 31(3):210-4.

9. Chen WL, Yang CM, Chen YF, Yang CH, Shau WY, Huang JS, Ho TC, Chen MS, Hung PT. Ciliary detachment after pars plana vitrectomy: an ultrasound biomicroscopic study. Retina. 2002;22(1):53-8.

10. Hikichi T, Ohnishi M, Hasegawa T. Transient shallow anterior chamber induced by supraciliary fluid after vitreous surgery. Am J Ophthalmol. 1997; 124(5):696-8.

11. Minamoto A, Nakano KE, Tanimoto S, Mizote H, Takeda Y. Ultrasound biomicroscopy in the diagnosis of persistent hypotony after vitrectomy. Am J Ophthalmol. 1997;123(5):711-3.

12. Ghomi Z, Ghassemi F. Changes in anterior segment parameters following pars Plana vitrectomy measured by ultrasound biomicroscopy (UBM). Medical hypothesis, discovery and innovation in ophthalmology. 2017;6(1):14-8. 
13. Benitez-Herreros J, Lopez-Guajardo L, Camara-Gonzalez C, Perez-Crespo A, Silva-Mato A, Alvaro-Meca A, Teus MA. Evaluation of conjunctival bleb detection after vitrectomy by ultrasound biomicroscopy, optical coherence tomography and direct visualization. Curr Eye Res. 2014;39(4):390-4.

14. Lopez-Guajardo L, Vleming-Pinilla E, Pareja-Esteban J, Teus-Guezala MA. Ultrasound biomicroscopy study of direct and oblique 25-gauge vitrectomy sclerotomies. Am J Ophthalmol. 2007;143(5):881-3.

15. Rizzo S, Genovesi-Ebert F, Vento A, Miniaci S, Cresti F, Palla M. Modified incision in 25-gauge vitrectomy in the creation of a tunneled airtight sclerotomy: an ultrabiomicroscopic study. Graefe's archive for clinical and experimental ophthalmology = Albrecht von Graefes Archiv fur klinische und experimentelle Ophthalmologie. 2007;245(9):1281-8.

16. X.B. Gao, X.L. Zhang, G. Chen, X.K. Huang, X.J. Zhong, M.K. Lin, J Ge, The blood-aqueous barrier changes after laser peripheral iridotomy or surgery peripheral iridectomy], [Zhonghua yan ke za zhi] Chinese journal of ophthalmology 2011:47(10): 876-880.

17. Sawa M. Laser flare-cell photometer: principle and significance in clinical and basic ophthalmology. Jpn J Ophthalmol. 2017;61(1):21-42.

18. Bernasconi O, Papadia M, Herbort CP. Sensitivity of laser flare photometry compared to slit-lamp cell evaluation in monitoring anterior chamber inflammation in uveitis. Int Ophthalmol. 2010;30(5):495-500.

19. Ho J, Grabowska A, Ugarte M, Muqit MM. A comparison of 23-gauge and 20-gauge vitrectomy for proliferative sickle cell retinopathy - clinical outcomes and surgical management. Eye (Lond). 2018:22.

20. Kim IG, Lee SJ, Park JM. Comparison of the 20-gauge conventional vitrectomy technique with the 23-gauge releasable suture vitrectomy technique. Korean J Ophthalmol. 2013;27(1):12-8.

21. Yokota R, Inoue M, Itoh Y, Rii T, Hirota K, Hirakata A. Comparison of microinsicion vitrectomy and conventional 20-gauge vitrectomy for severe proliferative diabetic retinopathy. Jpn J Ophthalmol. 2015;59(5):288-94.

22. Romero P, Salvat M, Almena M, Baget M, Mendez I. Experience with 25gauge transconjunctival vitrectomy compared to a 20-gauge system. Analysis of 132 cases. J Fr Ophtalmol. 2006;29(9):1025-32.

23. Chen E. 25-Gauge transconjunctival sutureless vitrectomy. Curr Opin Ophthalmol. 2007:18(3):188-93.

24. Miyake K, Masuda K, Shirato S, Oshika T, Eguchi K, Hoshi H, Majima Y, Kimura W, Hayashi F. Comparison of diclofenac and fluorometholone in preventing cystoid macular edema after small incision cataract surgery: a multicentered prospective trial. Jpn J Ophthalmol. 2000:44(1):58-67.

25. Laplace O, Goldschild M, De Saint Jean M, Guepratte N, Baudouin C Evaluation by laser flare meter of the inflammatory response after cataract surgery. J Fr Ophtalmol. 1998;21(4):265-9.

26. Tahiri Joutei Hassani R, El Sanharawi M, Adam R, Monin C, Dupont-Monod S, Baudouin C. Influence of sutureless 23-gauge sclerotomy architecture on postoperative intraocular pressure decrease: results of a multivariate analysis. Graefe's Arch Clin Exp Ophthalmol. 2013;251(5):1285-92.

27. Ho LY, Garretson BR, Ranchod TM, Balasubramaniam M, Ruby AJ, Capone A Jr, Drenser KA, Williams GA, Hassan TS. Study of intraocular pressure after 23-gauge and 25-gauge pars plana vitrectomy randomized to fluid versus air fill. Retina. 2011:31(6):1109-17.

Ready to submit your research? Choose BMC and benefit from:

- fast, convenient online submission

- thorough peer review by experienced researchers in your field

- rapid publication on acceptance

- support for research data, including large and complex data types

- gold Open Access which fosters wider collaboration and increased citations

- maximum visibility for your research: over $100 \mathrm{M}$ website views per year

At $\mathrm{BMC}$, research is always in progress.

Learn more biomedcentral.com/submissions 